\title{
POMC and TP53 genetic variability and risk of basal cell carcinoma of skin: Interaction between host and genetic factors
}

\author{
Cosmeri Rizzato ${ }^{\mathrm{a}, *}$, Dominique Scherer ${ }^{\mathrm{a}}$, Peter Rudnai ${ }^{\mathrm{b}}$, Eugen Gurzau ${ }^{\mathrm{c}}$, Kvetoslava Koppova ${ }^{\mathrm{d}}$, \\ Kari Hemminki ${ }^{\text {a,e }}$, Federico Canzian ${ }^{a}$, Rajiv Kumar ${ }^{a}$, Daniele Campa ${ }^{a}$ \\ ${ }^{a}$ German Cancer Research Center DKFZ, Heidelberg, Germany \\ ${ }^{\mathrm{b}}$ National Institute of Environmental Health, Budapest, Hungary \\ ${ }^{\mathrm{c}}$ Environmental Health Center, Cluj, Romania \\ d State Health Institute, Banska Bystrica, Slovakia \\ e Center for Primary Health Care Research, University of Lund, Malmö, Sweden
}

\section{A R T I C L E I N F O}

\section{Article history:}

Received 21 December 2010

Received in revised form 4 March 2011

Accepted 10 March 2011

\section{Keywords:}

Basal cell carcinoma of the skin

p53

POMC

Single nucleotide polymorphism

\begin{abstract}
A B S T R A C T
Background: Basal cell carcinoma (BCC) of the skin is the most common neoplasm among the Caucasian population of the western world. Ultraviolet (UV) radiation-induced p53 activation promotes cutaneous pigmentation by increasing transcriptional activity of pro-opiomelanocortin (POMC) in the skin. Induction of POMC/ $\alpha$-melanocyte-stimulating hormone ( $\alpha-\mathrm{MSH})$ activates the melanocortin 1 receptor (MC1R), resulting in skin pigmentation. The tumor suppressor p53 is a key player in stress responses that preserve genomic stability, responding to a variety of insults including DNA damage, hypoxia, metabolic stress and oncogene activation. Malfunction of the p53 pathway is an almost universal hallmark of human tumors. Polymorphisms in the gene encoding p53 (TP53) alter its transcriptional activity, which in turn may influence the UV radiation-induced tanning response.

Objective: The aim of the present work is to test association between POMC and TP53 genetic variability, the possible interplay with host factors and the risk of basal cell carcinoma of skin.

Methods: We covered the variability of the two genes we used 17 tagging polymorphisms in 529 BCC cases and 532 healthy controls. We have also tested the possible interactions between the genetic variants and three known risk factors for BCC: skin complexion, sun effect and skin response to sun exposure.

Results: We did not observe any statistically significant association between SNPs in these two genes and BCC risk overall, nor interactions of SNPs with known BCC risk factors. However we found that, in the group of subjects with lower sun exposure, carriers of one copy of the $C$ allele of the TP53 SNP rs12951053 had a decreased risk of BCC ( OR = 0.28, 95\% CI 0.12-0.62, $P=0.002)$.

Conclusions: We have observed that the interplay of an environmental risk factor and one polymorphism in TP53 gene could modulate the risk of BCC.
\end{abstract}

(C) 2011 Japanese Society for Investigative Dermatology. Published by Elsevier Ireland Ltd. All rights reserved.

\section{Introduction}

Basal cell carcinoma BCC of the skin is the most common neoplasm among the Caucasian population of the western world [1]. The risk for development of BCC is mainly associated with environmental factors (especially sun exposure) but also with genetic factors [2].

\footnotetext{
* Corresponding author at: Genomic Epidemiology Group, German Cancer Research Center DKFZ, Im Neuenheimer Feld 280, 69120 Heidelberg, Germany. Tel.: +496221 421814; fax: +496221 421810

E-mail address: c.rizzato@dkfz.de (C. Rizzato).
}

One of the main risk factors for BCC is ultraviolet (UV) radiation, through its induction of DNA damage [3-5]. Tanning is acquired pigmentation that results from exposure to UV, melanin synthesis by cutaneous melanocytes and transport into adjacent keratinocytes [6].

Melanin production is initiated by $\alpha$-melanocyte-stimulating hormone $(\alpha-\mathrm{MSH})$, which is produced by proteolysis from a multicomponent precursor polypeptide, encoded by the proopiomelanocortin (POMC) gene [7]. The induced POMC/ $\alpha-\mathrm{MSH}$ binds to MC1R, which further activates the cyclic adenosine monophosphate (cAMP) signalling system, leading to eumelanin production.

It has been shown that p53 is involved in cell-cycle arrest and apoptosis in response to UV-induced DNA damage [8,9]; moreover, 
Cui et al. [10] showed that the tumor-suppressor protein p53 promotes cutaneous pigmentation following UV irradiation by direct transcriptional activation of POMC in the skin and that p53 absence ablates the tanning response.

TP53 mutations have been detected in about half of all BCCs. Furthermore, it was found that aggressive forms of BCC are significantly associated with increased p53 expression [1,11].

This tumor suppressor gene is highly polymorphic: so far over 200 SNPs have been identified http://p53.free.fr; http://wwwp53.iarc.fr/ [12]. Few of the many TP53 polymorphisms have been assessed for altered biochemical and/or biological function, or for their effects on cancer risk in population studies [13]. The association between $\mathrm{p} 53$ codon 72 polymorphism and BCC risk has been investigated but the findings are controversial [14-17]. Another study investigated the association between BCC cancer risk and one SNP in the POMC gene with negative results [18].

In this study we investigated the effect of tagging and functional polymorphisms in the entire TP53 and POMC genes on well characterized BCC cases and controls. We analyzed TP53 and POMC jointly with $M C 1 R$ variants, which had been previously genotyped in the same cases and controls [19].

\section{Materials and methods}

\subsection{Study population}

A set of newly diagnosed cases and controls were recruited as part of a large study on risk of various cancers due to environmental arsenic exposure in Hungary, Romania and Slovakia between 2002 and 2004 [20]. The recruitment was carried out in the counties of Bacs, Csongrad and Jasz-Nagykun-Szolnok in Hungary; Bihor and Arad in Romania and Nitra in Slovakia. Skin cancer cases $(n=529)$ were invited on the basis of histopathological examinations by pathologists. Hospital-based controls $(n=532)$ were included in the study, subject to fulfillment of a set of criteria. All general hospitals in the study area were involved in the process of control recruitment and a rotation scheme was used in order to achieve appropriate geographical distribution. The controls were surgery, orthopedic and trauma patients with conditions such as appendicitis, abdominal hernias, duodenal ulcers, cholelithiasis and fractures; patients with malignant tumors, diabetes and cardiovascular diseases were excluded. The matching of the controls was done using this criteria: being of the same gender of the index case belonging to the same 5 years age band (30-34, 35-39, etc.), being of the same area. Moreover cases and controls were recruited among those individuals that have resided in the study area for at least one year during their lifetime) [21].

Subsequent to the signing of consent forms by the participants, clinicians took venous blood from cases and controls. The blood samples were kept deep frozen at $-80^{\circ} \mathrm{C}$ until analysis. A general questionnaire was completed by trained personnel after an interview of the recruited cases and controls. The questionnaire was designed to include information on individual cumulative sun exposure in summer, sun-tanning, skin-complexion, effects of sunexposure on skin and age/s at diagnosis of BCC; the Fitzpatrick classification was not used because of non-availability of facilities uniformly across all recruiting centers of the participating countries. In addition, the interviews included items on demographic, life-style, socio-economic, medical history, occupational exposures, drinking and nutritional habits, as well as detailed residential history. Ethnic background for the cases and controls was recorded along with other characteristics of the study population. Local ethical boards approved the study plan and design.

\subsection{Selection of polymorphisms}

We aimed at surveying the entire set of common genetic variants in TP53 and POMC genes. To this end we followed a hybrid functional/tagging approach using the algorithm described by Carlson and co-workers [22]. All polymorphisms in the region of TP53 gene including $5 \mathrm{~kb}$ upstream of the first exon and $5 \mathrm{~kb}$ downstream of the last exon with minor allele frequency MAF $\geq 5 \%$

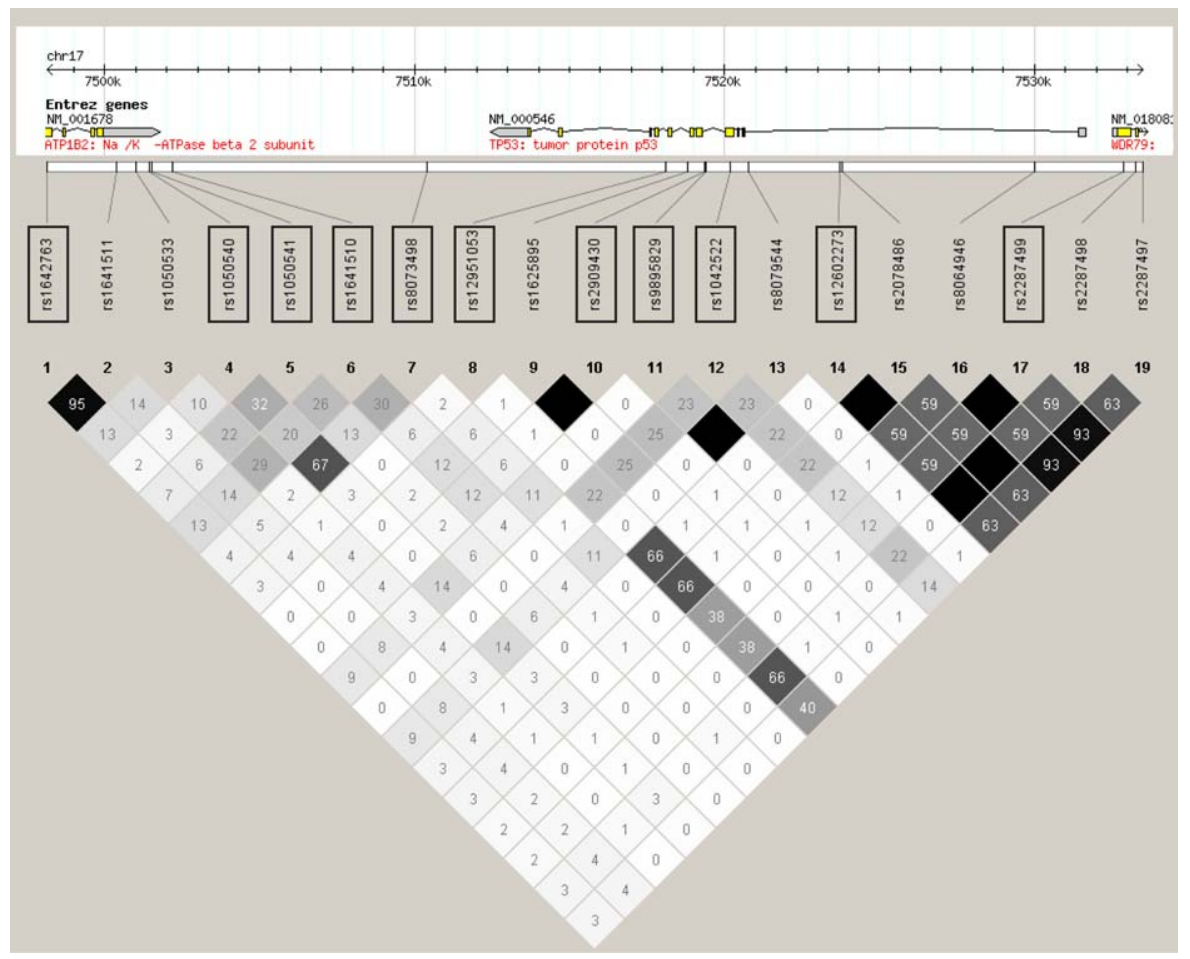

Fig. 1. Linkage disequilibrium (LD) plot across the TP53 locus, $r^{2}$ values are indicated in the plot. Selected SNPs are highlighted in square. 
in Caucasians from the International HapMap Project version 26 (http://www.hapmap.org) were included. Tagging SNPs were selected with the use of the Tagger program within Haploview (http://www.broadinstitute.org/mpg/haploview/; http:// www.broadinstitute.org/mpg/tagger/) [23,24], using pairwise tagging with a minimum $r^{2}$ of 0.8 (Fig. 1). We also included additional tagging SNPs selected among polymorphisms detected in a previous study [12]. We forced in the selection of tagging SNPs also rs1042522 Pro72Arg, which is a non-synonymous variant possibly implicated in risk of several cancer types. The SNP rs2909430 tags two other polymorphisms already found associated with cancer risk, a 16 bp duplication in the intron 3 rs17878362 [25] and a SNP in intron 6 rs1625895 [25].

SNPs selection for POMC has been described in a previous work [26] in which the selection has been done using an haplotypetagging approach according to the method of Stram et al. [27], with criterion $r_{\mathrm{H}}^{2}=0.7$.

\subsection{Genotyping}

The order of DNAs from cases and controls was randomized on PCR plates in order to ensure that an equal number of cases and controls could be analyzed simultaneously. All the genotyping was carried out using the Taqman assay. The MGB Taqman probes and primers were synthesized by Applied Biosystems (Foster City, CA, USA). PCRs were performed according to the manufacturer's instructions. PCR plates were read on an ABI PRISM 7900HT instrument by Applied Biosystems. MC1R gene has been genotyped by sequencing the amplification and sequencing conditions have been described previously [19].

\subsection{Statistical analysis}

The frequency distribution of genotypes was examined for cases and controls. Hardy-Weinberg equilibrium was tested in cases and in controls separately. The host factors, skin complexion and skin response to sun-exposure were categorized into high $(\mathrm{H}$ : light complexion or burns/blisters, respectively), medium (M: medium complexion or mild burns) and low (L: dark complexion or tan/no change) risk groups. Sun exposure was estimated by taking a mean of eight categorical variables measuring average daily exposure to the sun in over the respondents' lifetimes. The calculated mean was, then, divided in four categories corresponding to the hours of sun exposure during summer. The four cut-off points were $<2.5 \mathrm{~h} / 2.5-3.5 \mathrm{~h} / 3.6-4.5 \mathrm{~h} />4.5 \mathrm{~h}$. More detailed information has been previously reported [19].

We used logistic regression for multivariate analyses to assess the main effects of the genetic polymorphism on BCC risk. The primary end point of the analysis was cancer risk, measured with odds ratio and associated confidence intervals. All estimates were adjusted for age at diagnosis, gender, nationality and risk categories.

Considering the large number of comparison performed, we calculated for each gene the number of effective independent variables, $M_{\text {eff }}$, using the SNP Spectral Decomposition approach [28]. We obtained a gene-wide $M_{\text {eff }}$ value for each gene and also a study-wide $M_{\text {eff }}$ value, by adding up the gene $M_{\text {eff }}$ 's. The studywide $M_{\text {eff }}$ value was 12 , therefore we applied a study-wise threshold of significance of $P=0.0042(0.05 / 12)$, in order to interpret $P$-values in light of the multiple comparisons.

We analyzed associations of SNPs with BCC risk by grouping cases according to age, skin complexion, sun effect and skin response to sun exposure, we analyzed a model with the main effects for each SNP and the covariate of interest and a model where the SNP was parameterized nested within the covariate categories; we then computed the likelihood ratio test between the two models (heterogeneity test). Age was divided in 4 quartiles
( $<55$ years, $55-63$ years, $64-72,>72$ ). The host factor subgroups have been described above.

Logistic regression analyses and likelihood ratio test were done with STATA software (StataCorp, College Station, TX, USA).

The haplotype frequencies in cases and controls were inferred with the SAS/Genetics software module (SAS Institute Inc., Cary, NC, U.S.A.) using the expectation-maximization algorithm to generate maximum likelihood estimates. Samples missing one genotype or more were removed from haplotype analyses.

\subsection{Gene-gene and gene-environment interactions}

We analyzed all the possible pair-wise interactions between SNPs (gene-gene; G-G) and between SNPs and two host factors (skin complexion and skin response to sun exposure) and one environmental factor (sun exposure) (gene-environment; G-E). Assessment of G-G and G-E interactions was carried out using Multifactor Dimensionality Reduction (MDR). The details of MDR are described elsewhere [29-31]. Briefly, MDR is a data reduction approach that seeks to identify combinations of multilocus genotypes and discrete environmental factors that are associated with either high risk or low risk of disease. MDR defines a single variable that incorporates information from several loci and/or environmental factors. This new variable can be evaluated for its ability to classify and predict outcome risk status using crossvalidation and permutation testing. The MDR software is opensource and freely available from http://www.epistasis.org.

\subsection{Bioinformatics analysis}

Potential binding sites of transcription factors within the sequence encompassing the significantly associated SNP were performed with MatInspector Professional http://genomatix.de/ cgi-bin/matinspector_prof/mat_fam.pl [32].

\section{Results}

In this study 529 cases with BCC and 532 controls were recruited from Hungary, Romania and Slovakia. The mean age at

Table 1

Distribution of BCC cases and controls for different characteristics.

\begin{tabular}{|c|c|c|c|}
\hline Variable & Cases (\%) & Controls (\%) & $P$-value ${ }^{\mathrm{a}}$ \\
\hline Male & $237(44.8)$ & $274(51.4)$ & \\
\hline Female & $292(55.2)$ & $259(48.6)$ & \\
\hline Mean age ( \pm standard deviation) & $64.8( \pm 10.3)$ & $60.0( \pm 11.8)$ & \\
\hline Median age (25-75\% percentile) & $67(58-73)$ & $61(52-70)$ & \\
\hline \multicolumn{4}{|l|}{ Nationality } \\
\hline Hungarian & 208 (39) & $283(53)$ & \\
\hline Romanian & $125(24)$ & $118(22)$ & \\
\hline Slovak & $184(35)$ & $121(23)$ & \\
\hline Others & $12(2)$ & $10(2)$ & \\
\hline Skin complexion & & & $<0.0001$ \\
\hline Light & $280(53)$ & $212(40)$ & \\
\hline Medium & $233(44)$ & $261(49)$ & \\
\hline Dark & $16(3)$ & $59(11)$ & \\
\hline Skin response to sun-exposure & & & 0.04 \\
\hline Blistered/burnt & $185(35)$ & $141(26)$ & \\
\hline Mild burn & $169(32)$ & $159(30)$ & \\
\hline Tanning/no change & $175(33)$ & $232(44)$ & \\
\hline $\begin{array}{l}\text { Average cumulative sun exposure } \\
\text { (h per day during summer) }{ }^{\mathrm{b}}\end{array}$ & & & 0.59 \\
\hline$<2.4$ & $129(24)$ & $137(26)$ & \\
\hline $2.5-3.5$ & 151 (29) & $153(29)$ & \\
\hline $3.6-4.5$ & $135(26)$ & $111(21)$ & \\
\hline$>4.5$ & $112(21)$ & $125(23)$ & \\
\hline
\end{tabular}

${ }^{\text {a }} P$-value is for the effect of factor on BCC risk.

b Sun exposure estimated by calculating a mean of eight categorical variables measuring average daily exposure to the sun over the respondents' lifetimes. For two cases and six controls exposure information was not available. 
diagnosis of the cases (237 men and 292 women) was $64.8( \pm 10.3)$ years (median $67 ; 25-75 \%$ percentile $58-73$ ) and that of controls (274 men and 259 women) was $60.0( \pm 11.8)$ years (median $61 ; 25-75 \%$ percentile 52-70). While the complexion and nature of skin response to sun exposure showed association with BCC risk, the average cumulative sun-exposure was not associated with the risk Seventeen SNPs in TP53 and POMC genes were genotyped in each subject of the study and analyzed jointly with genotypes of MC1R SNPs we generated in a previous study [15]. Baseline characteristics of cases and controls are reported in Table 1. Genotype success rate for cases and controls was greater than 95\%. Blinded duplicate samples (6.2\%) included for quality control showed genotype concordance $>99 \%$. The genotype frequencies for all SNPs were in accordance with HardyWeinberg equilibrium in controls, and any deviation from the expected was not statistically significant (data not shown).The distribution of the genotypes and their odds ratios (ORs) for association with BCC risk are shown in Tables 2 and 3. The genotype frequencies of all SNPs were not found to be significantly different between cases and controls.

\section{1. $G-G, G-E$ interactions and subgroup analysis}

We have thoroughly analyzed all the possible pair-wise $\mathrm{G}-\mathrm{G}$ and G-E interactions between the selected SNPs in TP53, POMC and

Table 2

Associations between tagging SNPs in the TP53 gene region and BCC risk.

\begin{tabular}{|c|c|c|c|c|c|c|c|}
\hline Genotypes & Position $^{a}$ & Cases $(n=529)^{\mathrm{b}}$ & Controls $(n=532)^{\mathrm{b}}$ & $\mathrm{OR}^{\mathrm{c}}$ & $95 \% \mathrm{CI}^{\mathrm{C}}$ & $p$-Value & $P$ trend \\
\hline rs1642763 & $7,498,144$ ATP1B2, exon 4 & & & & 0.28 & & \\
\hline GG & & 325 & 343 & 1 (ref) & & & \\
\hline AG & & 169 & 145 & 1.15 & $(0.87-1.53)$ & 0.322 & \\
\hline $\mathrm{AA}$ & & 24 & 25 & 1.06 & $(0.58-1.96)$ & 0.845 & \\
\hline$A G+A A$ & & & & 1.14 & $(0.87-1.50)$ & 0.338 & \\
\hline rs1050540 & 7,501,467 ATP1B2, $3^{\prime}$ UTR & & & & & & \\
\hline $\mathrm{CC}$ & & 212 & 224 & 1 (ref) & & & 0.56 \\
\hline $\mathrm{CT}$ & & 239 & 224 & 1.09 & $(0.83-1.44)$ & 0.542 & \\
\hline TT & & 67 & 67 & 0.96 & $(0.64-1.45)$ & 0.859 & \\
\hline $\mathrm{CT}+\mathrm{TT}$ & & & & 1.06 & $(0.82-1.37)$ & 0.662 & \\
\hline rs1050541 & 7,501,560 ATP1B2, 3' UTR & & & & & & \\
\hline GG & & 137 & 143 & 1 (ref) & & & 0.93 \\
\hline GT & & 251 & 239 & 1.16 & $(0.85-1.59)$ & 0.338 & \\
\hline TT & & 125 & 133 & 1.05 & $(0.73-1.49)$ & 0.802 & \\
\hline $\mathrm{GT}+\mathrm{TT}$ & & & & 1.12 & $(0.84-1.50)$ & 0.438 & \\
\hline rs1641510 & $7,502,221$ intergenic & & & & & & \\
\hline $\mathrm{AA}$ & & 184 & 171 & 1 (ref) & & & 0.46 \\
\hline AG & & 236 & 247 & 0.93 & $(0.70-1.24)$ & 0.628 & \\
\hline GG & & 100 & 104 & 0.94 & $(0.66-1.35)$ & 0.742 & \\
\hline$A G+G G$ & & & & 0.93 & $(0.71-1.22)$ & 0.62 & \\
\hline rs8073498 & $7,510,423$ intergenic & & & & & & \\
\hline $\mathrm{AA}$ & & 184 & 198 & 1 (ref) & & & 0.19 \\
\hline AC & & 247 & 248 & 1.06 & $(0.80-1.40)$ & 0.682 & \\
\hline $\mathrm{CC}$ & & 88 & 73 & 1.20 & $(0.81-1.76)$ & 0.363 & \\
\hline $\mathrm{AC}+\mathrm{CC}$ & & & & 1.09 & $(0.84-1.43)$ & 0.512 & \\
\hline rs12951053 & $7,518,132$ TP53, intron 7 & & & & & & \\
\hline $\mathrm{AA}$ & & 440 & 437 & 1 (ref) & & & 0.55 \\
\hline$A C$ & & 79 & 79 & 0.97 & $(0.68-1.39)$ & 0.872 & \\
\hline $\mathrm{CC}$ & & 3 & 7 & 0.38 & $(0.09-1.65)$ & 0.198 & \\
\hline $\mathrm{AC}+\mathrm{CC}$ & & & & 0.92 & $(0.65-1.31)$ & 0.656 & \\
\hline rs2909430 & 7,519,370 ТР53, intron 4 & & & & & & \\
\hline TT & & 392 & 387 & 1 (ref) & & & 0.96 \\
\hline TC & & 103 & 112 & 1.01 & $(0.73-1.39)$ & 0.950 & \\
\hline $\mathrm{CC}$ & & 15 & 10 & 1.52 & $(0.64-3.60)$ & 0.340 & \\
\hline $\mathrm{TC}+\mathrm{CC}$ & & & & 1.05 & $(0.77-1.43)$ & 0.741 & \\
\hline rs9895829 & 7,519,404 TP53, intron 4 & & & & & & \\
\hline GG & & 390 & 388 & 1 (ref) & & & 0.99 \\
\hline GA & & 106 & 117 & 0.99 & $(0.72-1.36)$ & 0.960 & \\
\hline $\mathrm{AA}$ & & 13 & 8 & 1.65 & $(0.65-4.18)$ & 0.292 & \\
\hline $\mathrm{GA}+\mathrm{AA}$ & & & & 1.04 & $(0.76-1.40)$ & 0.819 & \\
\hline rs1042522 & 7,520,197 ТР53, exon 3 & & & & & & \\
\hline CC & & 292 & 297 & 1 (ref) & & & 0.91 \\
\hline CG & & 186 & 178 & 1.09 & $(0.83-1.44)$ & 0.523 & \\
\hline GG & & 40 & 46 & 0.91 & $(0.57-1.46)$ & 0.702 & \\
\hline $\mathrm{CG}+\mathrm{GG}$ & & & & 1.06 & $(0.82-1.37)$ & 0.679 & \\
\hline rs12602273 & 7,523,738 TP53, intron 1 & & & & & & \\
\hline $\mathrm{CC}$ & & 448 & 441 & 1 (ref) & & & 0.52 \\
\hline CG & & 68 & 78 & 0.85 & $(0.59-1.23)$ & 0.385 & \\
\hline GG & & 3 & 2 & 1.31 & $(0.19-9.2)$ & 0.789 & \\
\hline $\mathrm{CG}+\mathrm{GG}$ & & & & 0.86 & $(0.6-1.24)$ & 0.418 & \\
\hline rs2287499 & 7,532,893 WRAP53, exon 1 & & & & & & \\
\hline CC & & 406 & 397 & 1 (ref) & & & 0.19 \\
\hline CG & & 107 & 114 & 0.93 & $(0.68-1.27)$ & 0.631 & \\
\hline GG & & 5 & 12 & 0.46 & $(0.15-1.39)$ & 0.169 & \\
\hline $\mathrm{CG}+\mathrm{GG}$ & & & & 0.88 & $(0.65-1.2)$ & 0.43 & \\
\hline
\end{tabular}

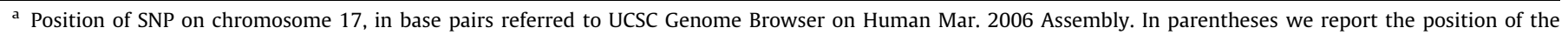
polymorphism with respect to the gene. Some SNPs are located in genes immediately flanking TP53 at the $3^{\prime}$ and 5'.

b Numbers may not add up to $100 \%$ of subjects due to genotyping failure.

c OR: odds ratio; CI: confidence interval. Adjusted for age, gender, nationality and host factors. 
Table 3

Associations between tagging SNPs in the POMC gene region and BCC risk.

\begin{tabular}{|c|c|c|c|c|c|c|c|}
\hline Genotypes & Position $^{a}$ & Cases $^{\mathrm{b}}$ & Controls $^{\mathrm{b}}$ & OR & $95 \% \mathrm{CI}$ & $P$-value & $P$ trend \\
\hline rs13002622 & $25,223,520$ & Intron, EFR3B & & & & & \\
\hline TT & & 248 & 236 & 1 (ref) & & & 0.42 \\
\hline TC & & 223 & 237 & 0.88 & $(0.67-1.15)$ & 0.363 & \\
\hline $\mathrm{CC}$ & & 45 & 48 & 0.95 & $(0.6-1.52)$ & 0.846 & \\
\hline $\mathrm{TC}+\mathrm{CC}$ & & & & 0.89 & $(0.69-1.16)$ & 0.395 & \\
\hline rs1866146 & $25,234,077$ & $3^{\prime}$ UTR, EFR3B & & & & & \\
\hline $\mathrm{AA}$ & & 186 & 194 & 1 (ref) & & & 0.55 \\
\hline AG & & 261 & 269 & 1.09 & $(0.82-1.44)$ & 0.551 & \\
\hline GG & & 70 & 63 & 1.17 & $(0.77-1.77)$ & 0.472 & \\
\hline $\mathrm{AG}+\mathrm{GG}$ & & & & 1.10 & $(0.85-1.44)$ & 0.469 & \\
\hline rs1042571 & $25,237,391$ & $3^{\prime}$ UTR, POMC & & & & & \\
\hline GG & & 361 & 366 & 1 (ref) & & & 0.56 \\
\hline GA & & 146 & 149 & 0.87 & $(0.65-1.15)$ & 0.327 & \\
\hline $\mathrm{AA}$ & & 14 & 8 & 1.96 & $(0.78-4.97)$ & 0.154 & \\
\hline $\mathrm{GA}+\mathrm{AA}$ & & & & 0.92 & $(0.69-1.21)$ & 0.546 & \\
\hline rs7566506 & $25,272,977$ & Intergenic & & & & & \\
\hline $\mathrm{CC}$ & & 447 & 447 & 1 (ref) & & & 0.47 \\
\hline $\mathrm{CA}$ & & 67 & 73 & 0.97 & $(0.67-1.41)$ & 0.871 & \\
\hline $\mathrm{AA}$ & & 3 & 5 & 0.64 & $(0.14-2.85)$ & 0.560 & \\
\hline $\mathrm{CA}+\mathrm{AA}$ & & & & 0.95 & $(0.66-1.37)$ & 0.775 & \\
\hline rs10202360 & $25,274,369$ & Intergenic & & & & & \\
\hline $\mathrm{AA}$ & & 334 & 327 & 1 (ref) & & & 0.59 \\
\hline$A C$ & & 172 & 175 & 1.05 & $(0.80-1.39)$ & 0.711 & \\
\hline $\mathrm{CC}$ & & 14 & 17 & 0.80 & $(0.38-1.72)$ & 0.574 & \\
\hline $\mathrm{AC}+\mathrm{CC}$ & & & & 1.03 & $(0.79-1.35)$ & 0.827 & \\
\hline rs28932474 & $25,383,068$ & Intergenic & & & & & \\
\hline GG & & 474 & 475 & 1 (ref) & & & 0.58 \\
\hline GC & & 48 & 54 & 0.86 & $(0.56-1.32)$ & 0.479 & \\
\hline $\mathrm{CC}$ & & 0 & 0 & & & & \\
\hline
\end{tabular}

a Position of SNP on chromosome 2, in base pairs referred to UCSC Genome Browser on Human Mar. 2006 Assembly. In parentheses we report the position of the polymorphism with respect to the gene.

b Numbers may not add up to $100 \%$ of subjects due to genotyping failure.OR: odds ratio; CI: confidence interval. Adjusted for age, gender, nationality and host factors.

MC1R by use of the MDR approach. Analysis using the MDR method with 10-fold cross validation did not reveal any statistically significant interaction (the best model described had cross validation consistency $9 / 10$, test balance accuracy 0.56 , OR 1.61 CI $0.74-3.49, P$ value $=0.23$ ). Analyzing the data in subgroups stratifying for age, gender and the host/environmental factors (skin complexion, sun exposure and skin response to sun exposure), we found that two polymorphic variants of TP53 had a study-wise $(P$ value $<0.0041)$ significant association with BCC risk. Results of subgroup analysis for rs12951053 and rs8073498 are reported in Table 4. Carriers of one copy of the C allele of rs12951053 had a decreased risk of BCC in the group of subjects with lower sun exposure during the summer $(\mathrm{OR}=0.28,95 \%$ CI $0.12-0.62$, $P=0.002$ ). Moreover, carriers of the $C$ allele of the same polymorphism show an increased risk in a group of subject with age ranged between 55 and 63 (OR $=2.67$ 95\% CI 1.27-5.64, $P=0.01)$ and subjects more prone to sun burns $(\mathrm{OR}=1.95,95 \% \mathrm{CI}$ $0.99-3.81, P=0.052$ ), even if these associations did not reach the threshold for multiple comparison analysis. When stratifying for sun exposure, the SNP rs12951053 had a heterogeneity test $P$ value of 0.0187 .

We observed an increased risk of BCC in carriers of one copy of the C allele of SNP rs8073498 in TP53 in the group of subjects with intermediate-high sun exposure during the summer $(\mathrm{OR}=2.83$, 95\% CI 1.50-5.35, $P=0.001$ ), although the heterogeneity test was not significant ( $p_{\text {heterogeneity }}=0.43$ ). Carriers of at least one copy of $\mathrm{C}$ allele show an association in this subgroup ( $\mathrm{OR}=2.32,95 \% \mathrm{CI}$ 1.29-4.16, $P=0.005$ ), even if this association did not reach the threshold for multiple comparison analysis. All the other polymorphisms, considering the various subgroups, did not show any statistically significant association. Supplementary Tables 1-4 show the analysis of each polymorphism of this study considering the various subgroups of age and sun-related exposures.
Haplotype analysis did not detect associations with BCC risk (showed in detail in Supplementary Table 5).

Searches for potential binding sites of transcription factors were performed with MatInspector within $100 \mathrm{bp}$ sequence surrounding rs12951053 and rs8073498. For the rs 12951053 the predicted binding of transcription factor did not differ between the two alleles.

Twenty-one binding sites for transcription factors were detected in the $100 \mathrm{bp}$ sequence surrounding the $\mathrm{A}$ allele of rs8073498. Four of those binding sites were abolished in the presence of the C allele (Fig. 2). Two of the abolished sites were for p53 (matrix similarity 0.94 and 0.98 ) and 2 for Iroquois homeobox transcription factors (not expressed in the skin).

\section{Discussion}

The risk for development of BCC is mainly associated with environmental factors (especially sun exposure) but also with genetic factors [2]. In this study we investigated the genetic variability of TP53 and POMC genes using a tagging approach and selecting 17 SNPs. Using this method we covered all the known common genetic variation of these genes, including polymorphisms coming from a recent study [12], but we did not find any significant difference of genotype and haplotypes distribution between cases and controls. Polymorphisms in TP53 have been found to be associated with cancer risk in a variety of tissues [3335].

Two studies found no association of the p53 codon 72 polymorphism with BCC risk [14,15], while in two others $[16,17]$ the polymorphism has been found associated.

In particular the same population, in which Han et al. reported an association between the p53 codon 72 polymorphism with tanning response for $\mathrm{BCC}$ risk in a prospective cohort of women, 
Table 4

Association of rs12951053 and rs8073498 with BCC risk by subgroups of environmental and host factors.

\begin{tabular}{|c|c|c|c|c|c|c|c|c|c|c|c|c|c|c|c|c|}
\hline & \multicolumn{3}{|c|}{ Cases } & \multicolumn{3}{|c|}{ Controls } & \multicolumn{2}{|c|}{ Per allele } & \multirow[t]{2}{*}{$P$ value } & \multicolumn{2}{|c|}{ AA vs. CC } & \multirow[t]{2}{*}{$P$ value } & \multicolumn{2}{|c|}{$A A$ vs. $(A C+C C)$} & \multirow[t]{2}{*}{$P$ value } & \multirow[t]{2}{*}{$P$ trend } \\
\hline & AA & $A C$ & CC & AA & $A C$ & $\mathrm{CC}$ & $\mathrm{OR}^{\mathrm{a}}$ & $95 \% \mathrm{Cl}^{\mathrm{a}}$ & & $\mathrm{OR}^{\mathrm{a}}$ & $95 \% \mathrm{Cl}^{\mathrm{a}}$ & & $\mathrm{OR}^{\mathrm{a}}$ & $95 \% \mathrm{CI}^{\mathrm{a}}$ & & \\
\hline \multicolumn{17}{|c|}{ rs12951053 } \\
\hline \multicolumn{17}{|c|}{ Sun-exposure $\left(P_{\text {heterogeneity }}=0.0187\right)^{\mathrm{b}}$} \\
\hline$>2.4$ & 120 & 11 & 0 & 108 & 30 & 0 & 0.28 & $(0.12-0.62)$ & 0.002 & & & & & & & \\
\hline $2.4-3.5$ & 96 & 17 & 2 & 104 & 9 & 2 & 1.91 & $(0.77-4.77)$ & 0.16 & 0.62 & $(0.07-5.52)$ & 0.67 & 1.66 & $(0.71-3.89)$ & 0.25 & 0.19 \\
\hline $3.6-4.5$ & 105 & 19 & 1 & 83 & 14 & 3 & 1.11 & $(0.51-2.42)$ & 0.78 & 0.33 & $(0.03-3.42)$ & 0.35 & 0.99 & $(0.47-2.06)$ & 0.97 & 0.58 \\
\hline$\geq 4.5$ & 119 & 32 & 0 & 142 & 26 & 2 & 1.36 & $(0.75-2.48)$ & 0.31 & & & & 1.28 & $(0.71-2.31)$ & 0.41 & 0.44 \\
\hline \multicolumn{17}{|c|}{ Skin response to sun effect ${ }^{\mathrm{C}}$} \\
\hline Blistered/burnt & 147 & 36 & 1 & 122 & 15 & 1 & 1.95 & $(0.99-3.81)$ & 0.05 & 0.76 & $(0.05-12.69)$ & 0.85 & 1.87 & $(0.97-3.59)$ & 0.06 & 0.06 \\
\hline Mild burn & 144 & 21 & 2 & 125 & 27 & 5 & 0.69 & $(0.36-1.33)$ & 0.27 & 0.37 & $(0.06-2.30)$ & 0.29 & 0.65 & $(0.35-1.20)$ & 0.17 & 0.08 \\
\hline Tanning/no change & 138 & 22 & 0 & 183 & 35 & 1 & 0.83 & $(0.46-1.52)$ & 0.55 & & & & 0.81 & $(0.44-1.46)$ & 0.48 & 0.41 \\
\hline \multicolumn{17}{|l|}{$\operatorname{Risk}^{\mathrm{c}}$} \\
\hline Low & 140 & 22 & 0 & 189 & 37 & 2 & 0.81 & $(0.45-1.46)$ & 0.48 & & & & 0.76 & $(0.42-1.38)$ & 0.37 & 0.26 \\
\hline Medium & 63 & 12 & 1 & 67 & 17 & 1 & 0.81 & $(0.35-1.90)$ & 0.63 & 1.57 & $(0.08-29.54)$ & 0.76 & 0.85 & $(0.37-1.93)$ & 0.69 & 0.57 \\
\hline High & 237 & 45 & 2 & 181 & 25 & 4 & 1.22 & $(0.71-2.11)$ & 0.47 & 0.31 & $(0.05-1.92)$ & 0.21 & 1.10 & $(0.65-1.86)$ & 0.72 & 0.68 \\
\hline \multicolumn{17}{|l|}{ Age $^{\mathrm{d}}$} \\
\hline$<55$ & 82 & 6 & 1 & 139 & 23 & 4 & 0.43 & $(0.16-1.15)$ & 0.09 & 0.35 & $(0.04-3.43)$ & 0.37 & 0.42 & $(0.17-1.04)$ & 0.06 & 0.07 \\
\hline $55-63$ & 87 & 25 & 0 & 113 & 13 & 1 & 2.67 & $(1.27-5.64)$ & $\underline{0.01}$ & & & & 2.51 & $(1.2-5.22)$ & $\underline{0.01}$ & 0.043 \\
\hline $64-72$ & 135 & 26 & 0 & 102 & 21 & 1 & 0.93 & $(0.49-1.77)$ & $\overline{0.83}$ & & & & 0.88 & $(0.47-1.66)$ & $\overline{0.69}$ & 0.60 \\
\hline$>72$ & 136 & 22 & 2 & 83 & 22 & 1 & 0.61 & $(0.31-1.22)$ & 0.16 & 1.10 & $(0.08-15.23)$ & 0.95 & 0.63 & $(0.33-1.24)$ & 0.18 & 0.22 \\
\hline \multicolumn{17}{|l|}{ Complexion $^{\mathrm{c}}$} \\
\hline Light & 235 & 40 & 2 & 174 & 31 & 4 & 0.87 & $(0.51-1.48)$ & 0.60 & 0.27 & $(0.04-1.73)$ & 0.17 & 0.80 & $(0.48-1.34)$ & 0.39 & 0.46 \\
\hline Medium & 191 & 36 & 1 & 211 & 41 & 2 & 0.96 & $(0.58-1.60)$ & 0.88 & 0.73 & $(0.06-8.73)$ & 0.80 & 0.95 & $(0.58-1.57)$ & 0.85 & 0.77 \\
\hline Dark & 13 & 3 & 0 & 51 & 7 & 1 & 1.90 & $(0.41-8.75)$ & 0.41 & & & & 1.62 & $(0.36-7.27)$ & 0.53 & 0.76 \\
\hline \multicolumn{17}{|l|}{ p53rs8073498 } \\
\hline \multicolumn{17}{|c|}{ Sun-exposure ${ }^{\mathrm{b}}\left(P_{\text {heterogeneity }}=0.4322\right)$} \\
\hline$>2.4$ & 51 & 59 & 20 & 44 & 78 & 17 & 0.59 & $(0.33-1.05)$ & 0.07 & 0.77 & $(0.34-1.76)$ & 0.540 & 0.63 & $(0.36-1.08)$ & 0.09 & 0.59 \\
\hline $2.4-3.5$ & 39 & 58 & 18 & 39 & 58 & 16 & 1.00 & $(0.54-1.84)$ & 0.10 & 0.95 & $(0.40-2.25)$ & 0.911 & 0.99 & $(0.55-1.77)$ & 0.97 & 0.82 \\
\hline $3.6-4.5$ & 38 & 69 & 18 & 48 & 34 & 17 & 2.83 & $(1.50-5.35)$ & 0.001 & 1.39 & $(0.61-3.18)$ & 0.431 & 2.32 & $(1.29-4.16)$ & $\underline{0.005}$ & 0.10 \\
\hline$\geq 4.5$ & 56 & 61 & 32 & 67 & 78 & 23 & 0.93 & $(0.56-1.55)$ & 0.79 & 1.57 & $(0.80-3.08)$ & 0.185 & 1.08 & $(0.67-1.73)$ & $\overline{0.75}$ & 0.21 \\
\hline Skin response to sun & $\mathrm{ffect}^{\mathrm{c}}$ & & & & & & & & & & & & & & & \\
\hline Blistered/burnt & 63 & 88 & 30 & 52 & 65 & 21 & 1.05 & $(0.63-1.74)$ & 0.86 & 1.09 & $(0.54-2.18)$ & 0.816 & 1.06 & $(0.65-1.71)$ & 0.82 & 0.59 \\
\hline Mild burn & 61 & 86 & 21 & 50 & 80 & 24 & 0.89 & $(0.54-1.49)$ & 0.67 & 0.69 & $(0.33-1.44)$ & 0.323 & 0.85 & $(0.52-1.37)$ & 0.50 & 0.35 \\
\hline Tanning/no change & 57 & 68 & 34 & 92 & 98 & 28 & 1.24 & $(0.77-2.00)$ & 0.37 & 1.68 & $(0.90-3.13)$ & 0.105 & 1.35 & $(0.87-2.1)$ & 0.18 & 0.05 \\
\hline $\operatorname{Risk}^{\mathrm{c}}$ & & & & & & & & & & & & & & & & \\
\hline Low & 57 & 70 & 34 & 94 & 105 & 28 & 1.19 & $(0.75-1.90)$ & 0.47 & 1.72 & $(0.92-3.20)$ & 0.088 & 1.31 & $(0.85-2.03)$ & 0.22 & 0.04 \\
\hline Medium & 30 & 38 & 9 & 29 & 41 & 13 & 1.01 & $(0.50-2.03)$ & 0.99 & 0.58 & $(0.20-1.65)$ & 0.309 & 0.89 & $(0.46-1.74)$ & 0.73 & 0.45 \\
\hline High & 97 & 139 & 45 & 75 & 102 & 32 & 0.98 & $(0.65-1.48)$ & 0.91 & 1.07 & $(0.60-1.89)$ & 0.824 & 1.00 & $(0.67-1.48)$ & 0.99 & 0.74 \\
\hline Age $^{\mathrm{d}}$ & & & & & & & & & & & & & & & & \\
\hline$<55$ & 28 & 44 & 15 & 67 & 76 & 23 & 1.56 & $(0.85-2.86)$ & 0.15 & 1.34 & $(0.59-3.04)$ & 0.488 & 1.50 & $(0.85-2.65)$ & 0.17 & 0.21 \\
\hline $55-63$ & 40 & 54 & 18 & 49 & 64 & 12 & 0.97 & $(0.55-1.72)$ & 0.92 & 1.77 & $(0.74-4.23)$ & 0.197 & 1.10 & $(0.64-1.88)$ & 0.74 & 0.25 \\
\hline $64-72$ & 58 & 80 & 24 & 40 & 64 & 19 & 0.83 & $(0.49-1.42)$ & 0.50 & 0.82 & $(0.39-1.73)$ & 0.607 & 0.83 & $(0.5-1.38)$ & 0.47 & 0.63 \\
\hline$>72$ & 58 & 69 & 31 & 42 & 44 & 19 & 1.13 & $(0.64-2.01)$ & 0.68 & 1.26 & $(0.61-2.59)$ & 0.539 & 1.17 & $(0.69-1.98)$ & 0.57 & 0.60 \\
\hline Complexion $^{\mathrm{b}}$ & & & & & & & & & & & & & & & & \\
\hline Light & 105 & 129 & 42 & 79 & 98 & 30 & 1.04 & $(0.69-1.58)$ & 0.84 & 0.99 & $(0.56-1.77)$ & 0.979 & 1.03 & $(0.70-1.52)$ & 0.88 & 0.89 \\
\hline Medium & 74 & 111 & 41 & 92 & 124 & 36 & 1.10 & $(0.73-1.66)$ & 0.65 & 1.28 & $(0.73-2.25)$ & 0.390 & 1.14 & $(0.77-1.69)$ & 0.51 & 0.23 \\
\hline Dark & 5 & 7 & 4 & 26 & 26 & 7 & 1.46 & $(0.40-5.37)$ & 0.57 & 2.58 & $(0.51-12.92)$ & 0.250 & 1.74 & $(0.52-5.75)$ & 0.37 & 0.19 \\
\hline
\end{tabular}

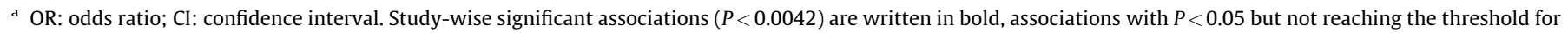
multiple comparison are underlined.

b Adjusted for age, gender, risk (which consists of the combination of skin complexion and skin response to sun exposure) and nationality.

c Adjusted for age, gender and nationality.

d Adjusted for gender, risk and nationality.

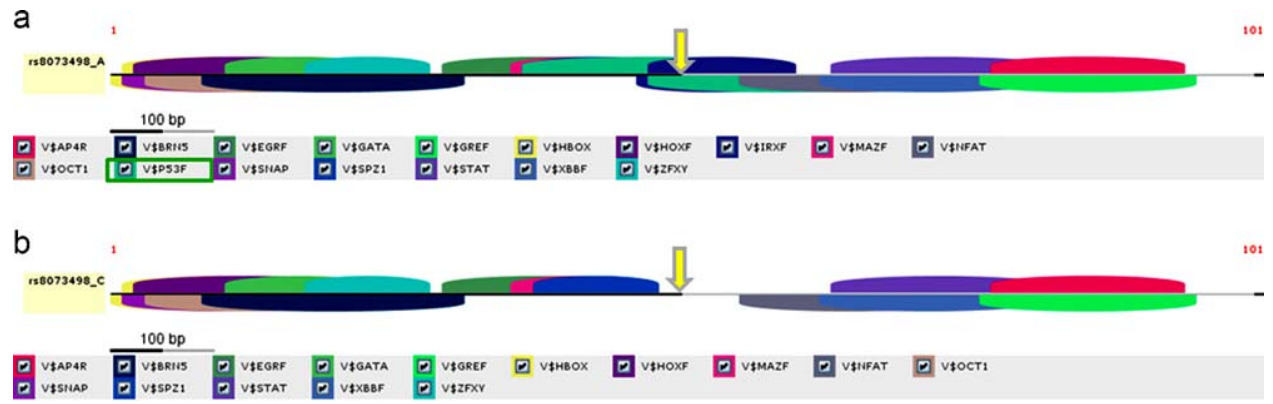

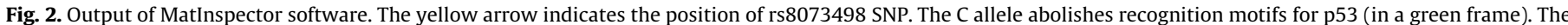

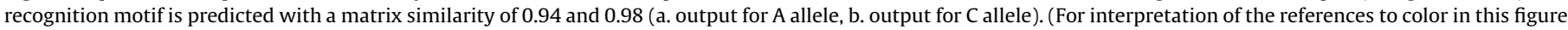
legend, the reader is referred to the web version of the article.) 
showed no association between one SNP in POMC gene (rs1042571) and BCC risk [18]. Our results show no association with the p53 codon 72 polymorphism, and confirm lack of association with $P O M C$ polymorphisms covering the whole gene, including rs1042571. Nan et al. [36] tested also an interaction analysis between $\mathrm{p} 53$ codon 72 polymorphism and MC1R variants. The authors found that there was an association between the two genes and melanoma risk but not for BCC risk. Our results on the interactions between the two gene variants confirm in a bigger independent population their null finding.

Sun exposure is the major etiological factor in the genesis of BCC; however, many studies have suggested that risk may involve an interplay between genetic (SNPs), host (skin complexion, skin response to sun exposure) and environmental (sun exposure) factors [2]. Thus we have thoroughly analyzed all the possible interactions and associations between the selected polymorphisms and known risk factors for BCC. Analyzing the data in subgroups stratifying for age, gender and the host factors previously mentioned, we found that two polymorphisms were associated with BCC risk. We found that, in the group of subjects with lower sun exposure during the summer, carriers of one copy of the C allele of the rs 12951053 had a decreased risk of BCC and subjects with intermediate-high sun exposure had an increased risk of BCC in carriers of one copy of the $C$ allele of SNP rs8073498, although the heterogeneity test in this subgroup analysis was not significant. The rs12951053 polymorphism has been found associated with increased risk in other cancer types [37-39]. On the other hand, we observed it to be associated with a decrease in BCC risk. p53 is known to act in many different ways, depending on the tissue and environmental stimuli; in this specific case its function is likely related with UV response. In different cancer types the major function can be a different one with different regulations. In silico analysis predicts that several variants in moderate LD $\left(0.5<r^{2}<0.7\right)$ with TP53 rs12951053 can affect a transcription factor binding site; in addition, rs2287498, which is in the flanking gene WDR79 and in LD with rs12951053 $\left(r^{2}=0.62\right)$, is predicted to affect function at a splice site [39]. The mRNA encoding this protein plays a critical role in the regulation of $\mathrm{p} 53$ expression at the post-transcriptional level; it is involved both in maintaining basal p53 mRNA levels and in p53 induction upon DNA damage [40]. So far there is no published association between genotypes in rs8073498 and cancer risk. We assessed the putative effect of the C allele by the MatInspector program, which predicts that this variant may abolish recognition motifs for p53 itself (Fig. 2).

In this study we had more than $80 \%$ power to detect a possible association with a minimum OR of 1.28 for a SNP with minor allele frequency of 0.45 in the controls assuming alpha $=0.05$, two-sided test and a codominant model. In conclusion, we have observed that the interplay of sun exposure and one polymorphism in TP53 gene association could modulate the risk of BCC. However these results have to be taken with caution due to the relatively large number of comparisons done and have to be replicated in a larger independent study.

\section{Appendix A. Supplementary data}

Supplementary data associated with this article can be found, in the online version, at doi:10.1016/j.jdermsci.2011.03.006.

\section{References}

[1] Miller DL, Weinstock MA. Nonmelanoma skin cancer in the United States: incidence. J Am Acad Dermatol 1994;30(5, Part 1):774-8.

[2] Kumar R. Molecular epidemiology of skin cancer. In: Ringborg U, Brandeber Y, Breitbart E, et al., editors. Prevention of skin cancer. London: Informa Healthcare; 2006. p. 225-40.
[3] Armstrong BK, Kricker A, English DR. Sun exposure and skin cancer. Australias J Dermatol 1997:38(Suppl. 1):S1-6.

[4] Brash DE. Sunlight and the onset of skin cancer. Trends Genet 1997;13:410-4.

[5] English DR, Armstrong BK, Kricker A, Fleming C. Sunlight and cancer. Cancer Causes Control 1997;8:271-83.

[6] Lin JY, Fisher DE. Melanocyte biology and skin pigmentation. Nature 2007;445:843-50.

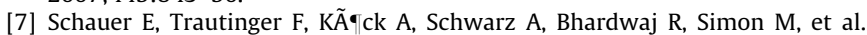
Proopiomelanocortin-derived peptides are synthesized and released by human keratinocytes. J Clin Invest 1994;93:2258-62.

[8] Hussain SP, Hollstein MH, Harris CC. p53 tumor suppressor gene: at the crossroads of molecular carcinogenesis molecular epidemiology, and human risk assessment. Ann N Y Acad Sci 2000;919:79-85.

[9] Olivier M, Eeles R, Hollstein M, Khan MA, Harris CC, Hainaut P. The IARC TP53 database: new online mutation analysis and recommendations to users. Hum Mutat 2002;19:607-14.

[10] Cui R, Widlund HR, Feige E, Lin JY, Wilensky DL, Igras VE, et al. Central role of p53 in the suntan response and pathologic hyperpigmentation. Cell 2007; 128:853-64.

[11] Tilli CM, Van Steensel MA, Krekels GA, Neumann HA, Ramaekers FC. Molecular aetiology and pathogenesis of basal cell carcinoma. $\mathrm{Br} \mathrm{J}$ Dermatol 2005;152:1108-24.

[12] Garritano S, Gemignani F, Voegele C, Nguyen-Dumont T, Le Calvez-Kelm F, De Silva $\mathrm{D}$, et al. Determining the effectiveness of high resolution melting analysis for SNP genotyping and mutation scanning at the TP53 locus. BMC Genet 2009; $10: 5$.

[13] Whibley C, Pharoah PD, Hollstein M. p53 polymorphisms: cancer implications. Nat Rev Cancer 2009;9:95-107.

[14] Almquist LM, Karagas MR, Christensen BC, Welsh MM, Perry AE, Storm C, et al. The role of TP53 and MDM2 polymorphisms in TP53 mutagenesis and risk of non-melanoma skin cancer. Carcinogenesis 2011;32:327-30.

[15] Bendesky A, Rosales A, Salazar AM, Sordo M, Peniche J, Ostrosky-Wegman P. p53 codon 72 polymorphism, DNA damage and repair, and risk of nonmelanoma skin cancer. Mutat Res 2007;619:38-44.

[16] Chen YC, Xu L, Guo YL, Su HJ, Hsueh YM, Smith TJ, et al. Genetic polymorphism in 533 codon 72 and skin cancer in southwestern Taiwan. J Environ Sci Health A Tox Hazard Subst Environ Eng 2003;38:201-11.

[17] Han J, Cox DG, Colditz GA, Hunter DJ. The p53 codon 72 polymorphism, sunburns, and risk of skin cancer in US Caucasian women. Mol Carcinogen 2006;45:694-700.

[18] Nan H, Kraft P, Hunter DJ, Han J. Genetic variants in pigmentation genes, pigmentary phenotypes, and risk of skin cancer in Caucasians. Int J Cancer 2009;125:909-17.

[19] Scherer D Bermejo JL, Rudnai P Gurzau E, Koppova K, Hemminki K, et al. MC1R variants associated susceptibility to basal cell carcinoma of skin: interaction with host factors and XRCC3 polymorphism. Int J Cancer 2008;122:1787-93.

[20] Lindberg AL, Goessler W, Gurzau E, Koppova K, Rudnai P, Kumar R, et al. Arsenic exposure in Hungary, Romania and Slovakia. J Environ Monit 2006;8:203-8

[21] Thirumaran RK, Bermejo JL, Rudnai P, Gurzau E, Koppova K, Goessler W, et al. Single nucleotide polymorphisms in DNA repair genes and basal cell carcinoma of skin. Carcinogenesis 2006;27:1676-81.

[22] Carlson CS, Eberle MA, Rieder MJ, Yi Q Kruglyak L, Nickerson DA. Selecting a maximally informative set of single-nucleotide polymorphisms for association analyses using linkage disequilibrium. Am J Hum Genet 2004;74:106-20.

[23] Barrett JC, Fry B, Maller J, Daly MJ, Haploview:. analysis and visualization of LD and haplotype maps. Bioinformatics 2005;21:263-5.

[24] de Bakker PI, Yelensky R, Pe'er I, Gabriel SB, Daly MJ, Altshuler D. Efficiency and power in genetic association studies. Nat Genet 2005;37:1217-23.

[25] Lazar V, Hazard F, Bertin F, Janin N, Bellet D, Bressac B. Simple sequence repeat polymorphism within the p53 gene. Oncogene 1993;8:1703-5.

[26] Canzian F, Cox DG, Setiawan VW, Stram DO, Ziegler RG, Dossus L, et al Comprehensive analysis of common genetic variation in 61 genes related to steroid hormone and insulin-like growth factor-I metabolism and breast cancer risk in the $\mathrm{NCI}$ breast and prostate cancer cohort consortium. Hum Mol Genet 2010;19:3873-84.

[27] Stram DO, Haiman CA, Hirschhorn JN, Altshuler D, Kolonel LN, Henderson BE, et al. Choosing haplotype-tagging SNPS based on unphased genotype data using a preliminary sample of unrelated subjects with an example from the multiethnic cohort study. Hum Hered 2003;55:27-36.

[28] Gao X, Starmer J, Martin ER. A multiple testing correction method for genetic association studies using correlated single nucleotide polymorphisms. Genet Epidemiol 2008;32:361-9.

[29] Marylyn DR, Lance WH, Jason HM. Power of multifactor dimensionality reduction for detecting gene-gene interactions in the presence of genotyping error, missing data, phenocopy, and genetic heterogeneity. Genet Epidemiol 2003;24:150-7.

[30] Moore JH. Computational analysis of gene-gene interactions using multifactor dimensionality reduction. Expert Rev Mol Diagn 2004:4:795-803.

[31] Ritchie MD, Hahn LW, Roodi N, Bailey LR, Dupont WD, Parl FF, et al. Multifactor-dimensionality reduction reveals high-order interactions among estrogenmetabolism genes in sporadic breast cancer. Am J Hum Genet 2001;69: 138-47.

[32] Cartharius K, Frech K, Grote K, Klocke B, Haltmeier M, Klingenhoff A, et al. MatInspector and beyond: promoter analysis based on transcription factor binding sites. Bioinformatics 2005;21:2933-42. 
[33] Boldrini L, Gisfredi S, Ursino S, Lucchi M, Greco G, Mussi A, et al. Effect of the p53 codon 72 and intron 3 polymorphisms on non-small cell lung cancer (NSCLC) prognosis. Cancer Invest 2008;26:168-72.

[34] Gemignani F, Moreno V, Landi S, Moullan N, Chabrier A, Gutierrez-Enriquez S, et al. A TP53 polymorphism is associated with increased risk of colorectal cancer and with reduced levels of TP53 mRNA. Oncogene 2004;23:1954-6.

[35] Wang-Gohrke S, Weikel W, Risch H, Vesprini D, Abrahamson J, Lerman C, et al. Intron variants of the $\mathrm{p} 53$ gene are associated with increased risk for ovarian cancer but not in carriers of BRCA1 or BRCA2 germline mutations. Br J Cancer 1999;81:179-83.

[36] Nan H, Qureshi AA, Hunter DJ, Han J. Interaction between p53 codon 72 polymorphism and melanocortin 1 receptor variants on suntan response and cutaneous melanoma risk. Br J Dermatol 2008;159:314-21.
[37] Garcia-Closas M, Kristensen V, Langerod A, Qi Y, Yeager M, Burdett L, et al. Common genetic variation in TP53 and its flanking genes WDR79 and ATP1B2, and susceptibility to breast cancer. Int J Cancer 2007;121:2532-8.

[38] Koshiol J, Hildesheim A, Gonzalez P, Bratti MC, Porras C, Schiffman M, et al. Common genetic variation in TP53 and risk of human papillomavirus persistence and progression to CIN3/cancer revisited. Cancer Epidemiol Biomarkers Prev 2009;18:1631-7.

[39] Schildkraut JM, Iversen ES, Wilson MA, Clyde MA, Moorman PG, Palmieri RT, et al. Association between DNA damage response and repair genes and risk of invasive serous ovarian cancer. PLoS One 2010;5:e10061.

[40] Mahmoudi S, Henriksson S, Corcoran M, Mendez-Vidal C, Wiman KG, Farnebo M. Wrap53, a natural p53 antisense transcript required for p53 induction upon DNA damage. Mol Cell 2009;33:462-71. 